Services was highlighted. Induction and in- service training now includes education on consent and good record keeping for all grades of staff. Re-audit in 12 months to ensure improvement continues

\section{P88 USING AN OUTCOME MEASURE IN SPECIALIST PALLIATIVE CARE SETTINGS}

Gail Walker, Evelyn Cochrane. NHS Tayside, Dundee, Scotland

\subsection{6/bmjspcare-2013-000591.110}

Background More and more people are living with chronic disease near the end of their life, therefore palliative care needs are increasing. Outcome measurement has a major role to play in improving the quality, efficiency and availability of palliative care.

Aim To capture what patients think about the impact of care on quality of life and their major concerns and on key symptoms. Method Patients were invited to participate in a 6-month pilot using the St Christopher's Index of Patient Priorities (SKIPP) questionnaire within the Hospice, Day Care and Community Macmillan Nurse Team.

Data was collected and analysed using the recognised tool from St Christopher's Hospice.

Results Findings from this pilot would suggest that patients did benefit from input from the Hospice, Day Care or Community Macmillan Nurse Team and identified a positive shift in how things were going for patients over a period of time. Though the number of patients was small and there were some patients who were unable to complete the questionnaire in full, there was still significant evidence to suggest a positive impact on patients' quality of life, key symptoms and major concerns.

Discussion It is recognised that obtaining valid and reliable measurement of the outcomes achieved by palliative care for patients is extremely challenging often because patients are too ill or because of fluctuating and changing needs. However the questionnaire takes account of response shift, a well known phenomenon in which a persons' perception of subjective sensations can change over time.

Conclusion Having a tool such as SKIPP has been deemed a very useful way of evaluating the impact three areas within Specialist Palliative Care have on a patients quality of life, key symptoms and major concerns. It is planned to repeat this exercise again for a 6 month period.

\section{P89 YOU DON'T GET A SECOND CHANCE TO MAKE A FIRST IMPRESSION...}

Jane Finnerty, Chris Haywood, John Ellis, lan Turnbull, Debbie Jones, Pat Bennett. Willowbrook Hospice, Prescot, UK

10.1136/bmjspcare-2013-000591.111

Background/context Fostering good first impressions of a care setting are an important component of building confidence and providing reassurance for patient's, carers, relatives and visitors. The 15 Steps Challenge is a toolkit devised by the NHS Institute for Innovation and Improvement in 2012 to help staff, patients and others to identify improvements that enhance the patient experience and environment. Initially 15 Steps was developed for use in Hospital wards but we adapted it for the whole Hospice environment.
Aims To use an accredited quality improvement tool and clear framework to facilitate in depth observations of quality care across four domains:

1. Welcoming

2. Safe

3. Caring and Involvement

4. Well organised and calm

Approach used

- Readily available easy to use literature to guide implementation

- PowerPoint slides for awareness sessions and training

- Small team to undertake the review (included 1 patient/carer representative, 1 non-clinical staff and 2 clinical staff)

- Dedicated toolkit

- Engagement with internal stakeholders

- A structured walk around the entirety of the Hospice environment

- Presentations to different staff groups on findings

- Focus on positive feedback and sharing good practice

- Repeated at 6 months to show achievements and improvements

Outcomes Explicit patient/carer perspectives were taken into account.

Detailed action plans with key positive impacts on the working environment.

Supports the Care Quality Commission's Essential Standards

Case study for evaluation (IES) by telephone survey.

Application to Hospice Practice

- Use of the 15 Steps toolkit clearly effective as a quality improvement initiative

- Re-audit has shown improvements in all domains

- Heightened staff awareness; quality is everyone's business

- Strengthened communication across services

- Adaptable for use in Fundraising/Trading Company improving quality across the organisation.

- The Challenge can be repeated on a regular basis to cover all areas and to ensure that improvements are being progressed and maintained.

\section{P90 DELIVERING AN INTEGRATED END OF LIFE CARE SERVICE FOR GREENWICH - THE BENEFITS AND LEARNING TWO YEARS ON}

Kate Heaps. Greenwich \& Bexley Community Hospice, London, UK

10.1136/bmjspcare-2013-000591.112

Background The Greenwich Care Partnership (GCP) was born out of the Marie Curie Delivering Choice Programme (DCP). Three service providers were asked to develop the service, the Hospice acts as the prime contractor and sub-contracts others to deliver specific elements of the service.

Aim The service aims to increase the number of people who die in their place of choice by ensuring that appropriate health and personal care services are available and that their families have sufficient support.

Approach used The service operates alongside core services to support high quality care across four areas:

- Care co-ordination

- Rapid Response Service 